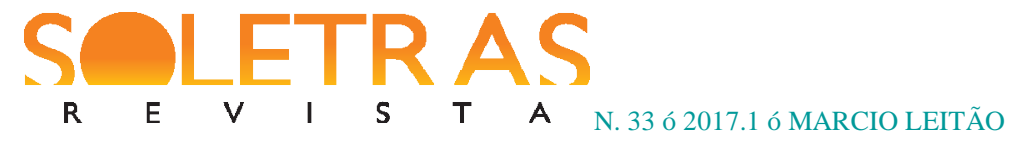

\title{
Entrevista
}

\section{Laboratório de Processamento Linguístico (LAPROL)}

Marcio Leitão ${ }^{1}$

Universidade Federal da Paraíba

\section{Entrevista concedida aos professores Kátia Abreu e Eduardo Kenedy}

Soletras: Quando o seu LAB foi fundado? Qual foi sua experiência em LABs de Psicolinguística anterior à fundação do LAB que coordena?

O LAPROL ï Laboratório de Processamento Linguístico da UFPB foi fundado em 2007, um ano depois que passei no concurso para UFPB. Na época, tive a ajuda inestimável da professora Maria de Fátima Melo do Nascimento, que me ajudou a montar o laboratório e também participou das nossas primeiras pesquisas. Depois, ela mudou de área de atuação, mas a gratidão ficará sempre registrada. Antes disso, a minha experiência em LABs de Psicolinguística ocorreu no meu período de doutoramento na UFRJ, em que trabalhei no LAPEX ï Laboratório de Psicolinguística Experimental da UFRJ, coordenado pelo professor Marcus Maia, então meu orientador. Logo após a defesa da minha tese de doutorado, também passei quase 9 meses trabalhando como professor visitante no atual NEALP ï Núcleo de Estudos em Aquisição da Linguagem e Psicolinguística da UFJF, coordenado pela professora Cristina Name. Essas duas experiências e, particularmente, a convivência com o professor Marcus Maia e com a professora Cristina Name e também com os colegas docentes e discentes que formavam as equipes dos laboratórios foram fundamentais para meu crescimento acadêmico e para que eu pudesse fundar o LAPROL, sendo este um dos primeiros laboratórios em Psicolinguística Experimental no Nordeste.

Soletras: Quais os principais temas de pesquisa que seu LAB vem contemplando ao longo dos anos?

O LAPROL tem como temas de pesquisa o processamento linguístico no nível morfológico e sintático, além do processamento correferencial que abrange desde questões mais estruturais a questões na interface sintaxe-semântica e sintaxe-pragmática. Além desses

\footnotetext{
${ }^{1}$ Professor adjunto da Universidade Federal da Paraíba (UFPB).profleitao@gmail.com 


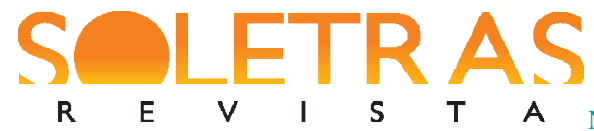

níveis e do trabalho focalizando o processamento linguístico em adultos, temos executado pesquisas sobre o processamento em bilíngues e em indivíduos que têm algum tipo de déficit ou patologia relacionados à linguagem (Dislexia, afasia, Alzheimer, gagueira). Com a chegada do professor José Ferrari Neto, em 2010, o laboratório também tem executado pesquisas na interface Aquisição e Processamento da Linguagem, em que se estuda o público infantil. Hoje em dia, temos como pesquisadores do LAPROL na UFPB, além de mim, o professor José Ferrari Neto, a professora Rosana Costa de Oliveira e o professor Giorvan Anderson Alves que foi nosso aluno de doutorado e que hoje nos ajuda na parceria com a área de Fonoaudiologia da UFPB.

Soletras: Quais as principais técnicas experimentais que vêm sendo empregadas nas pesquisas de seu Lab nos últimos anos?

A técnica mais utilizada nas pesquisas do laboratório sem sombra de dúvida é a Leitura Automonitorada, que permite medidas online e tem um ótimo custo-benefício, já que se pode executá-la com poucos recursos. Além da Leitura Automonitorada, utilizamos outras técnicas comportamentais, como priming, julgamento controlado de gramaticalidade, leitura automonitorada de palavra isolada, Cross-modal Picture select task e fixação do olhar em experimentos com crianças. Em parceria com outros laboratórios (LAPEX-UFRJ, Laboratório de Psicolinguística e Ciências Cognitivas ï UFC), também executamos estudos utilizando a técnica de monitoramento ocular (Eyetracking). Atualmente, conseguimos comprar um equipamento de EEG e juntamente com pesquisadores do Programa de Pós-graduação em Neurociências da UFPB, estamos em fase de aprendizagem da técnica para que em trabalhos futuros possamos também utilizá-la, já que acreditamos que quanto mais possibilidades metodológicas o laboratório tiver acesso, mais abrangentes e precisas serão as pesquisas e as respectivas análises.

Soletras: Você poderia fazer uma estimativa do total de pesquisas de mestrado e doutorado que foram conduzidas no Lab?

24 dissertações de mestrado concluídas e 06 teses de doutorado, além de mais de 17 orientações de Iniciação Científica que são também cruciais para que o laboratório se renove e se mantenha vivo e atuante. 
Soletras: O Lab integra alguma rede de cooperação? Poderia citar outros Labs parceiros?

No LAPROL, sempre buscamos trabalhar em parceria com outros laboratórios. Temos em nosso grupo de pesquisa do $\mathrm{CNPq}$ vários pesquisadores de outros laboratórios nacionais, como o LAPEX-UFRJ (Professor Marcus Maia), o Laboratório de Psicolinguística e Ciências Cognitivas da UFC (Professora Elisângela Teixeira), O Laboratório de Psicolinguística da UFMG (Professor Ricardo Sousa) e o Grupo de Estudos em Psicolinguística Experimental ï GEPEX-UFF (Professor Eduardo Kenedy). Além disso, mantemos colaboração com a Professora Elaine Grolla da USP e os professores Rafael Minussi e Indaiá Bassani da UNIFESP e a professora Ruth Lopes da UNICAMP, fruto do Pós-doutorado do professor José Ferrari Neto na UNICAMP. Mantemos também colaboração ativa com vários laboratórios e pesquisadores internacionais, como o Laboratório de Psicolinguística e Cognição da Universidade de Concórdia no Canadá (Professor Roberto de Almeida), o Laboratório de Psicolinguística da Universidade de Lisboa (Professoras Armanda Costa e Paula Luegi) e o grupo de pesquisa da Universidade do Minho (Professora Maria do Carmo Lourenço-Gomes), a colaboração com as universidades em Portugal são fruto do meu Pós-doutorado na Universidade de Lisboa.

Soletras: Deixe uma palavra de seu Lab para os leitores alunos de graduação interessados em ingressar na área da psicolinguística experimental.

Apesar de atravessarmos nos últimos anos um processo de retrocesso no Brasil, que tem já se refletido fortemente nas condições de operação e de trabalho das universidades federais e estaduais, acho que ainda é possível uma palavra de otimismo para quem deseja começar ou continuar atuando na área de Psicolinguística Experimental. Desde que finalizei meu doutorado em 2005, vi ocorrer um aumento de laboratórios que trabalham na pesquisa em Psicolinguística Experimental. Hoje encontramos mais de um laboratório em várias regiões do Brasil, que até então não existiam e que vêm fazendo um trabalho bastante relevante na direção do crescimento das pesquisas da área, ao meu ver, com qualidade. Junto a isso, mesmo com esse aumento de laboratórios e pesquisadores, a área ainda tem muito que crescer e há muito que se pesquisar sobre o processamento da linguagem e suas interfaces. Portanto, vamos lutar para conseguir seguir em frente.

Entrevista realizada em 05 de junho de 2017.

SOLETRAS ï Revista do Programa de Pós-Graduação em Letras e Linguística ï PPLIN 